\title{
Pure sensory neuropathy in patients with primary Sjögren's syndrome: clinical, immunological, and electromyographic findings
}

\author{
J Font, J Valls, R Cervera, A Pou, M Ingelmo, F Graus
}

\begin{abstract}
A pure sensory neuropathy caused by lymphocytic infiltration of the dorsal root ganglia has been reported in a few patients with Sjögren's syndrome. The clinical, immunological, and electromyographic findings of five patients with this type of neuropathy and primary Sjögren's syndrome were reviewed. Typical clinical indications were the presence of a chronic asymmetrical sensory deficit, initial disease in the hands with a predominant loss of the vibratory and joint position senses, and an association with Adie's pupil syndrome or trigeminal sensory neuropathy. The simultaneous impairment of the central and peripheral evoked cortical potentials suggested that there was a lesion of the neuronal cell body. The neuropathy preceded the diagnosis of Siögren's syndrome in four patients. Four patients were positive for Ro antibodies, but systemic vasculitis or malignancy was not found after a mean follow up of six years. These findings indicate that in patients with a sensory neuropathy the diagnosis of Sjögren's syndrome has to be considered, even if the patient denies the presence of sicca symptoms, and that appropriate tests must be carried out.
\end{abstract}

Sjögren's syndrome is a chronic, multisystem immunological disorder that is characterised by progressive destruction of the exocrine glands, accompanied by a variety of autoimmune phenomena. This syndrome can present either as a primary disorder or as a component of other autoimmune diseases, such as rheumatoid arthritis, scleroderma, or systemic lupus erythematosus. ${ }^{1}$ Virtually any organ system of the body can be affected. ${ }^{1}$ The most characteristic symptoms are keratoconjunctivitis sicca and xerostomia, resulting from a destructive mono- syndrome and a new type of sensory neuropathy due to lymphocytic infiltration of the dorsal root ganglia. $^{7-12}$ In some of these case reports the clinical setting of this neuropathy was not completely defined, and the description of isolated cases prevented identification of the main clinical and neurophysiological features that would have been helpful in its diagnosis. The recognition of this sensory neuropathy, however, is important because it usually precedes the diagnosis of Sjögren's syndrome, it is not associated with systemic vasculitis, and treatment with corticosteroids may not be appropriate.

The purpose of this study was to analyse the clinical, immunological, and electromyographic findings of a series of five patients with primary Sjögren's syndrome and pure sensory neuropathy to determine the most characteristic features which distinguish this neuropathy from the more common neuropathies observed in primary Sjögren's syndrome.

\section{Patients and methods}

PATIENTS

The clinical, immunological, and electromyographic features of five women with pure sensory neuropathy associated with primary Sjögren's syndrome, and diagnosed in our hospital were reviewed. Two of them (patients 4 and 5 ; table 1 ) have already been reported. ${ }^{11}$ The median age was $\mathbf{4 4 \cdot 4}$ years (range 28-75 years). All but one patient were first seen because of the neurological deficit. The onset of neurological symptoms was asymmetrical, insidious, and in the arms in all the patients. Presenting clinical manifestations were numbness, paraesthesias, and difficulty in identifying objects with the affected hand. The symptoms slowly progressed over the ensuing years to affect asymmetrically both upper and lower extremities. All patients had had long periods (years) during which the neuropathy seemed to have stabilised.

All patients had Sjögren's syndrome defined according to the more commonly used criteria. ${ }^{13}$ Keratoconjunctivitis sicca was confirmed by a positive Schirmer's test and characteristic rose bengal staining. Xerostomia was confirmed by an abnormal salivary gland scintigram and a positive minor salivary gland biopsy specimen. A work-up to identify an occult malignancy yielded negative results in all the patients, and other causes of keratoconjunctivitis sicca, ${ }^{14}$ xerostomia, ${ }^{14}$ and sensory neuropathy ${ }^{15}$ were excluded. All the patients were prospectively studied by the authors after sensory neuropathy \footnotetext{
nuclear infiltration of the lachrymal and salivary glands, respectively. Similar mononuclear infiltrates invading visceral organs can give rise to such extraglandular manifestations as interstitial pulmonary fibrosis, ${ }^{2}$ renal tubular acidosis, ${ }^{3}$ and Hashimoto's thyroiditis. ${ }^{4}$

Neurological features are well documented in primary Sjögren's syndrome, and peripheral nervous system disease is reported in $10-32 \%$ of patients with this disorder ${ }^{5}$ : mixed polyneuropathy confined to the lower extremities and mononeuritis multiplex are the most commonly observed. ${ }^{5}$ These neuropathies occur after the diagnosis of Siögren's syndrome is well established and they are usually associated with systemic vasculitis. 5 There have recently been

reports of a few patients with primary Sjögren's

Correspondence to: Dr Graus.

Accepted for publication

3 October 1989

Department

Villarroel 170,

J Font

Neurology

Department of

Nuestra Seł̌ora del Mar,

Barcelona, Spai
} 
Table 1: Sensory neuropathy and primary Sjögren's syndrome: neurological manifestations

\begin{tabular}{|c|c|c|c|c|c|c|c|c|c|}
\hline \multirow{2}{*}{$\begin{array}{l}\text { Patient } \\
\text { No }\end{array}$} & \multirow[t]{2}{*}{ Age/sex } & \multirow{2}{*}{$\begin{array}{l}\text { Duration of } \\
\text { neuropathy } \\
\text { (years) }\end{array}$} & \multirow{2}{*}{$\begin{array}{l}\text { Cranial } \\
\text { nerves }\end{array}$} & \multicolumn{4}{|c|}{ Sensory disturbances* } & \multirow{2}{*}{$\begin{array}{l}\text { Deep } \\
\text { tendon } \\
\text { reflexes }\end{array}$} & \multirow{2}{*}{$\begin{array}{l}\text { Muscle } \\
\text { strength }\end{array}$} \\
\hline & & & & Right arm & Right leg & Left arm & Left leg & & \\
\hline $\begin{array}{l}1 \\
2 \\
3 \\
4 \\
5\end{array}$ & $\begin{array}{l}33 / \mathbf{F} \\
28 / \mathbf{F} \\
28 / \mathbf{F} \\
58 / \mathbf{F} \\
75 / \mathbf{F}\end{array}$ & $\begin{array}{r}6 \\
6 \\
13 \\
7 \\
5\end{array}$ & $\begin{array}{l}\text { Adie's pupil } \\
\text { Adie's pupil } \\
\text { Adie's pupil } \\
\text { Trigeminal sensory neuropathy } \\
\text { Trigeminal sensory neuropathy }\end{array}$ & $\begin{array}{l}\text { Moderate } \\
\text { Severe } \\
\text { Moderate } \\
\text { Moderate } \\
\text { Severe }\end{array}$ & $\begin{array}{l}\text { Mild } \\
\text { Mild } \\
\text { Normal } \\
\text { Mild } \\
\text { Severe }\end{array}$ & $\begin{array}{l}\text { Mild } \\
\text { Moderate } \\
\text { Moderate } \\
\text { Mild } \\
\text { Severe }\end{array}$ & $\begin{array}{l}\text { Mild } \\
\text { Mild } \\
\text { Normal } \\
\text { Mild } \\
\text { Severe }\end{array}$ & $\begin{array}{l}\text { Abolished } \\
\text { Abolished } \\
\text { Abolished } \\
\text { Abolished } \\
\text { Abolished }\end{array}$ & $\begin{array}{l}\text { Normal } \\
\text { Normal } \\
\text { Normal } \\
\text { Normal } \\
\text { Normal }\end{array}$ \\
\hline
\end{tabular}

*Impairment of joint position and vibratory senses over other sensory modalities in all cases.

Mild=symptoms do not interfere with daily activities; moderate=clinical symptoms cause some limitations in daily activities; severe=extremity practically useless because of the proprioceptive deficit.

had been diagnosed, with a follow up ranging from two to 13 years.

\section{ELECTROMYOGRAPHIC STUDIES}

Needle electromyography (EMG) was performed in the distal muscles of the hands and feet. Conventional neuropathic studies of motor and sensory conduction velocity and compound action potential amplitude were carried out in the common peroneal, posterior tibial, sural, median, and ulnar nerves. Long latency reflex responses were studied in the arms and legs: $H$ reflex was tested in soleus muscles, $T$ wave was tested in soleus and biceps brachii muscles, and $F$ wave was examined in posterior tibial and median nerves. Somatosensory evoked cortical potentials recorded on the scalp were tested bilaterally by the stimulation of the median nerve at the wrist and the posterior tibial nerve at the ankle. Blink reflex was studied in both eyes by the electrical stimulation of the supraorbital nerve. The electromyograph used in the study was an MS8 MEDELEC (Old Woking, Surrey, England). All tests were performed using routine techniques ${ }^{16}$ and standard equipment and electrodes.

\section{IMMUNOLOGICAL STUDIES}

Antinuclear antibodies (ANAs) were determined by indirect immunofluorescence using mouse liver as substrate. Rheumatoid factor was tested by latex fixation (positive titre $\geqslant 1 / 40$ ). Anti-dsDNA antibodies were determined with Farr's ammonium sulphate precipitation technique. ${ }^{17}$ Antibodies to extractable nuclear anti-

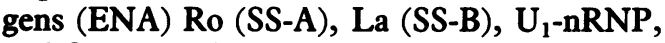
and $\mathrm{Sm}$ were detected by counterimmunoelectrophoresis using human spleen and calf thymus extracts. ${ }^{18}$ Antimitochondrial and anti-smooth muscle antibodies were detected by indirect immunofluorescence using rat kidney and stomach as substrates. ${ }^{19}$ The presence of antibodies against neural antigens was evaluated by indirect immunofluorescence on frozen sections of normal human dorsal root ganglia, as described previously. ${ }^{20}$ Circulating immune complexes were detected by $\mathrm{Clq}$ binding assay ${ }^{21}$ and cryoglobulins by immunoelectrophoresis. ${ }^{22}$ Complement components ( $\mathrm{C} 3$ and $\mathrm{C} 4$ ) were estimated by radial immunodiffusion and $\mathrm{CH}_{50}$ by Lachmann's haemolytic technique. ${ }^{23}$

\section{Results}

Neurological findings are summarised in table 1. Pupils were poorly reactive to light and severely constricted in response to $0.1 \%$ pilocarpine (Adie's pupil syndrome) in three patients; in two the defect was bilateral. Sensory trigeminal neuropathy was also present in two patients. All modalities of sensation were asymmetrically affected. The sensory loss affecting the vibratory and joint position senses was disproportionate to the loss of light touch or pinprick sensations, which were slightly impaired. Pseudoathetotic movements were observed in the hand where the deficit was severe. In the patient with the most severe neuropathy such movements were present in all four extremities. Deep tendon reflexes were absent in all patients. The rest of the neurological examination yielded normal results.

At the time of the neurological evaluation, only one patient (No 1) had had Sjögren's syndrome diagnosed, nine years previously. Two patients spontaneously complained of symptoms suggestive of sicca syndrome. In one (patient No 5) only xerostomia was found at the time of diagnosis but keratoconjunctivitis sicca was present one year later. The remaining two denied the presence of such symptoms, but in one sicca syndrome was confirmed by Schirmer's test, rose bengal staining, parotid scintigraphy, and minor salivary gland biopsy. The other patient was not specifically evaluated for xerostomia and keratoconjunctivitis sicca at the time of the initial presentation in 1976 but she developed full-blown sicca syndrome in 1987.

Electromyographic results are summarised in table 2 . The needle biopsy study showed no signs of denervation. The results of the neurographic tests of motor nerves were normal. F wave was present in all nerves examined, but $\mathrm{H}$

Table 2: Sensory neuropathy and primary Sjögren's syndrome: electrophysiological results

\begin{tabular}{|c|c|c|c|c|c|}
\hline & \multicolumn{5}{|c|}{ Patient No } \\
\hline & 1 & 2 & 3 & 4 & 5 \\
\hline $\begin{array}{c}\text { EMG, CMAP, F wave } \\
\text { SNAP Right sural } \\
\text { Left sural } \\
\text { Right median } \\
\text { Left median } \\
\text { Right ulnar } \\
\text { Left ulnar } \\
\text { SEP Right median } \\
\text { Left median } \\
\text { Right tibial } \\
\text { Left tibial } \\
\text { H reflex soleus } \\
\text { T wave (soleus, biceps) } \\
\text { BR Right side stimulus } \\
\text { Left side stimulus }\end{array}$ & $\begin{array}{l}\text { N } \\
\text { A } \\
\text { A } \\
\text { A } \\
\text { L } \\
\text { A } \\
\text { A } \\
\text { L } \\
\text { L } \\
\text { ND } \\
\text { ND } \\
\text { A } \\
\text { A } \\
\text { D } \\
\text { D }\end{array}$ & $\begin{array}{l}\text { N } \\
\mathbf{L} \\
\mathbf{L} \\
\mathbf{A} \\
\mathbf{L} \\
\mathbf{A} \\
\mathbf{A} \\
\mathbf{A} \\
\mathbf{L} \\
\mathbf{L} \\
\mathbf{L} \\
\mathbf{A} \\
\mathbf{A} \\
\mathbf{D} \\
\mathbf{N}\end{array}$ & $\begin{array}{l}\mathbf{N} \\
\mathbf{L} \\
\mathbf{N} \\
\mathbf{A} \\
\mathbf{A} \\
\mathbf{A} \\
\mathbf{A} \\
\mathbf{A} \\
\mathbf{A} \\
\mathbf{N} \\
\mathbf{N} \\
\mathbf{A} \\
\mathbf{A} \\
\mathbf{D} \\
\mathbf{D}\end{array}$ & $\begin{array}{l}\mathbf{N} \\
\mathbf{A} \\
\mathbf{A} \\
\mathbf{A} \\
\mathbf{A} \\
\mathbf{A} \\
\mathbf{A} \\
\mathbf{A} \\
\mathbf{A} \\
\mathbf{A} \\
\mathbf{A} \\
\mathbf{N D} \\
\mathbf{N D} \\
\mathbf{N D} \\
\mathbf{N D}\end{array}$ & $\begin{array}{l}\mathbf{N} \\
\mathbf{A} \\
\mathbf{A} \\
\mathbf{A} \\
\mathbf{A} \\
\mathbf{A} \\
\mathbf{A} \\
\mathbf{A} \\
\mathbf{A} \\
\mathbf{A} \\
\mathbf{A} \\
\mathbf{A} \\
\mathbf{A} \\
\mathbf{A} \\
\mathbf{A}\end{array}$ \\
\hline
\end{tabular}

$\mathrm{N}=$ normal; $\mathrm{A}=$ absent; $\mathrm{L}=$ low amplitude; $\mathrm{D}=$ delayed; $\mathrm{ND}=$ not done; $\mathbf{E M G}=$ needle electromyography; $\mathrm{CMAP}=$ compound muscle action potential; SNAP = sensory nerve action potentials; SEP=somasthetic evoked cortical potentials; $\mathrm{BR}=$ blink reflex. 
reflexes and $\mathrm{T}$ waves were absent in all patients. Most of the neurographic tests of sensory nerves showed abnormal results, often with absent responses. Nevertheless, in three patients some nerves had normal or low amplitude responses, reflecting asymmetrical clinical disease. Somatosensory evoked cortical potentials recorded on the scalp were not obtained when tested in those nerves with absent sensory action potentials. Blink reflexes were absent or delayed in the four patients examined.

Positive ANA tests were seen in two patients (Nos 1 and 3) up to a titre of 1/400. Rheumatoid factor was positive at $1 / 80$ in two patients (Nos 2 and 3). Four patients were positive for Ro (SSA) antibodies and three for La (SS-B). All patients were negative for DNA binding, RNP, $\mathrm{Sm}$, antimitochondrial, and anti-smooth muscle antibodies. Circulating immune complexes were present in patient 1 , and cryoglobulins were not detected. Complement components were normal in all patients. No patient showed the presence of specific antibodies against neural antigens. Nuclear or nucleolar staining of neurones was at the same titre as that seen in other nuclei, suggesting that the pattern was due to the presence of Ro or La antibodies.

To date, the mean duration of our patients' neuropathy has been $7 \cdot 4$ years (five to 13 ). All but one patient remain ambulatory in spite of the neurological symptoms. In these patients the principal impairment was usually the proprioceptive defect present in the hand affected at the onset of the neuropathy. One patient (No 3) still has the sensory deficit confined to the arms 13 years after the onset of neuropathy (table 1). On the other hand, the neuropathy in patient No 5 took a severe progressive course two years after the onset of the disease in spite of treatment with high doses of prednisone (1 $\mathrm{mg} / \mathrm{kg}$ daily). Two patients (Nos 1 and 3) received low doses of prednisone ( $5 \mathrm{mg}$ daily) because of sicca syndrome without an apparent improvement in neuropathy. The other two patients received no treatment. During follow up none of the patients developed systemic vasculitis or lymphoma; patient No 2 developed Hashimoto's thyroiditis.

\section{Discussion}

Unlike previous case reports our study shows that not only can neuropathy precede the diagnosis of Sjögren's syndrome but it may be present even when a definite diagnosis of Sjögren's syndrome cannot be made. Therefore, appropriate tests must be repeated during follow up to confirm the diagnosis of Sjögren's syndrome. Moreover, the present series shows that these patients have remarkably similar clinical and electromyographic features, which differentiate this neuropathy from the more common neuropathies caused by vasculitic disease of the peripheral nerve. In all our patients symptoms started in one hand and slowly progressed to the other extremities. The neuropathy remained asymmetrical even years after its onset. All modalities of sensation were usually affected but there was always a predominance of the vibratory and joint position senses. Adie's pupil syndrome was observed in three of our patients. Autonomic polyneuropathy has been described in Sjögren's syndrome associated with sensory ${ }^{9}$ or sensorimotor neuropathy. ${ }^{6}$ Our patients did not complain of other symptoms of autonomic dysfunction but no studies were done to determine if a more widespread subclinical autonomic neuropathy was present.

The absence of motor weakness, the presence of an asymmetrical sensory neuropathy initially affecting the arms, the fact that the vibratory and joint position senses syndrome rather than other modalities of sensation were affected, and the association with Adie's pupil syndrome or trigeminal sensory neuropathy are clues to the clinical diagnosis of this neuropathy. Some of these features, however, are also described in patients with Sjögren's syndrome and neuropathies due to necrotising vasculitis in the peripheral nerve. ${ }^{6}$ Therefore, a complete electromyographic evaluation is mandatory to document the selective sensory dysfunctions.

The results of the electromyographic examination of our patients were homogeneous and strongly suggest that the neurological lesion lies in the neurones of the dorsal root and Gasserian ganglia. Normal motor nerve and F wave studies, together with abnormal sensory nerve and $H$ reflex and $T$ wave studies, indicate that there is a selective lesion of the sensory pathways at the level of the neurone itself or at the peripheral axon. Absence of somatosensory evoked cortical potentials in nerves with absent responses to sensory neurographic tests indicates that the lesion itself should be located at the cell body. This was only observed in one previous case report ${ }^{7}$ and its finding in our five patients affirms that somatosensory evoked cortical potentials must be included in the electromyographic work-up of patients with sensory neuropathies to corroborate the theory that the dorsal root ganglia are affected.

Interestingly, the clinical and immunological setting of this sensory neuropathy in Sjögren's syndrome differs from the more common sensorimotor neuropathies due to neutrophilic vasculitis. ${ }^{5}$ In the latter the neuropathy usually occurs after the diagnosis of Sjögren's syndrome is well established, and it is associated with the presence of rheumatoid factor, immune complexes, and hypocomplementaemia. ${ }^{5}$ These immunological abnormalities were not present in our patients. In previous case reports the association of the sensory neuropathy with Ro or $\mathrm{La}$ antibodies was unclear. The incidence of these antibodies is usually increased in patients with systemic vasculitis and mixed polyneuropathy. ${ }^{5}$ Four out of five patients, however, had positive Ro antibodies, even though none had evidence of systemic vasculitis. Although the role of the Ro and $\mathrm{La}$ antibodies in the pathogenesis of the sensory neuropathy is unknown, the high incidence of positive Ro antibodies suggests that they may be helpful in the current diagnosis of patients with sensory neuropathy of unclear origin.

In conclusion, we believe that in patients with a sensory neuropathy, with the clinical and electromyographic features reported above, the diagnosis of Sjögren's syndrome has to be con- 
sidered even if the patient denies the presence of sicca symptoms. Thus appropriate tests, including minor salivary gland biopsy and tests for Ro and La antibodies, have to be undertaken. If the initial screening is negative the test should be repeated later because, as seen in three of our patients, definite Sjögren's syndrome was only diagnosed years after the onset of the neuropathy. In patients with known Sjögren's syndrome the differentiation of this neuropathy from those due to necrotising vasculitis has important therapeutic implications. Whereas the latter usually improves with corticosteroids $^{56}$ no improvement of the pure sensory neuropathy has been described with immunosuppressive drugs. On the other hand, if the neuropathy is diagnosed when the patient is minimally disabled, treatment with corticosteroids would not be necessary if it is borne in mind that the course of the neuropathy is chronic and sometimes benign and that vasculitis is absent.

We acknowledge the technical assistance of Ms María Jesús Iranzo.

1 Chused T M, Mann D L, Klippel J M, et al. Siögren's syndrome (sicca syndrome): current issues. Moutsopoulos H M (moderator) Ann Intern Med 1980; 92: 212-26.

2 Constantopoulos S H, Moutsopoulos H M. The respiratory system in Siögren's syndrome. In: Talal N, Moutsopoulos system in Siögren's syndrome. In: Talal N, Moutsopoulo immunological aspects. Berlin: Springer, 1987: 96-101.

3 Shiozawa S, Shiozawa K, Shimizu S, Nakada M, Isobe T Fujita T. Clinical studies of renal disease in Sjögren's syndrome. Ann Rheum Dis 1987; 46: 768-72.

4 Saad-Dine Y, Macurak R B, Beasley E W. Hashimoto's thyroiditis, pernicious anemia, Siögren's syndrome, and CREST syndrome-a case report. F Med Assoc Ga 1981 70: 187-9.

5 Alexander E L, Provost T T, Stevens M B, Alexander G E. Neurologic complications of primary Sjögren's syndrome. Medicine (Baltimore) 1982; 61: 247-57.

6 Mellgren S I, Conn D L, Stevens J C, Dyck P J. Peripheral neuropathy in primary Siögren's syndrome. Neurology neuropathy in 1989 ; 39 : $390-4$.

7 Malinow K, Yannakakis G D, Glusman S M, et al. Subacute sensory neuropathy secondary to dorsal root ganglionitis in primary Siögren's syndrome. Ann Neurol 1987; 20: in primar.

8 Hull R G, Morgan S H, Harding A E, Hughes G R V. Sjögren's syndrome presenting as a severe neuropathy
including involvement of the trigeminal nerve. $\mathrm{Br} \mathcal{F}$ including involvement of

9 Kennett R P, Harding A E. Peripheral neuropathy associated with the sicca syndrome. F Neurol Neurosurg Psychiatry 1986; 49: 90-2.

10 Hankey G J, Gubbay S S. Peripheral neuropathy associated with sicca syndrome. $\mathcal{F}$ Neurol Neurosurg Psychiatry 1987; 50: 1085

11 Graus F, Pou A, Kanterewicz E, Anderson N E. Sensory neuropathy and Sjögren's syndrome: clinical and immunologic study of two patients. Neurology 1988; 38: 1637-9.

12 Laloux P, Brucher J M, Guerit J M, Sindic C J M, Laterre E C. Subacute sensory neuropathy associated with E C. Subacute sensory neuropathy associated

13 Fox R I, Robinson C A, Curd J G, Kozin F, Howell F V. Siögren's syndrome: proposed criteria for classification Arthritis Rheum 1986; 29: 577-85.

14 Morrow J, Isenberg D. Sjögren's syndrome. In: Autoimmune rheumatic diseases. Oxford: Blackwell Scientific, 1987: 208-33.

15 Dalakas M C. Chronic idiopathic ataxic neuropathy. Ann Neurol 1986; 19: 545-54.

16 Kimura J. Electrodiagnosis in diseases of the nerve and muscle: Principles and practice. Philadelphia: F A Davis. 1983: 83-104.

17 Wold R T, Young F E, Tan E M, Farr E R S. Deoxyribonucleic acid antibody: a method to detect its primary nucleic acid antibody: a method to detect its primary interaction 8 .

18 Johnson A M. Immunoelectrophoresis. In: Rose $N \mathbf{R}$ Friedman A, Fahey J L, eds. Manual of clinical laboratory immunology. 3rd ed. Washington, DC: American Society for Microbiology, 1986: 20-1.

19 Bigazzi P E, Burek C L, Rose N R. Antibodies to tissuespecific endocrine, gastrointestinal, and neurological antigens. In: Rose N R, Friedman H, Fahey I L, eds. Manual of clinical laboratory immunology. 3rd ed. Washington, DC: Ámerican Society for Microbiology, 1986: 765

20 Graus F, Elkon K B, Cordon-Cardo C, Posmer J B. Sensory neuropathy and small cell lung cancer: an antineuronal neuropathy and small cell lung cancer: an antineuronal antibody the $45-52$.

21 Toth C A, Ohl D, Agnello V. Methods for detection of immune complexes by utilizing $\mathrm{C}_{1 \mathrm{q}}$ or rheumatoid factors. In: Rose N R, Friedman H, Fahey J L, eds. Manual of clinical laboratory immunology. 3rd ed. Washington, DC American Society for Microbiology, 1986: 204-10.

22 Kyle $R$ A. Classification and diagnosis of monoclonal gammopathies. In: Rose $\mathbf{N} R$, Friedman $\mathrm{H}$, Fahey J L, eds. Manual of clinical laboratory immunology. 3rd ed. Washington, DC: American Society for Microbiology, 1986: 152-67.

23 Lachmann P J, Hobart M J. Complement technology. In Handbook of experimental immunology. Vol 1. London: Handbook of experimental
Blackwell Scientific, 1978. 